\title{
Erratum to: Increased Regional Epicardial Fat Volume Associated with Reversible Myocardial Ischemia in Patient's with Suspected Coronary Artery Disease
}

Tuba Khawaja, MD, ${ }^{\text {a }}$ Christine Greer, BS, ${ }^{a}$ Samir R. Thadani, MD, ${ }^{b}$

Tomoko S. Kato, MD, ${ }^{a}$ Ketan Bhatia, BS, ${ }^{a}$ Daichi Shimbo, MD, ${ }^{a}$ Andrew Kontak, $M D,{ }^{a}$ Sabahat Bokhari, MD, ${ }^{a}$ Andrew J. Einstein, $M D, P h D,{ }^{a}$ and

P. Christian Schulze, MD, PhD ${ }^{a}$

a Division of Cardiology, Department of Medicine, New York-Presbyterian Hospital/Columbia University Medical Center, New York, NY

${ }^{b}$ Division of Cardiology, Department of Medicine, Kaiser Permanente South San Francisco Medical Center, South San Francisco, CA

doi:10.1007/s12350-015-0107-6

\section{ERRATUM TO: J NUCL CARDIOL \\ DOI: 10.1007/S1 2350-014-0004-4}

The seventh author's last name was misspelled as "Konkak" in the published article. The correct spelling is "Kontak", as it appears in the author list of this erratum.

The online version of the original article can be found under doi:10.1007/s12350-014-0004-4.

Reprint requests: P. Christian Schulze, MD, PhD, Division of Cardiology, Department of Medicine, New York-Presbyterian Hospital/ Columbia University Medical Center, 622 W168th Street, PH10203, New York, NY, 10032, USA; pcs2121@columbia.edu J Nucl Cardiol 2015;22:589.

$1071-3581 / \$ 34.00$

Copyright (C) 2015 American Society of Nuclear Cardiology. 